\title{
Reflexiones jurídicas sobre la prohibición de contenidos terroristas en internet
}

\author{
Legal Reflections on the Prohibition of
} Terrorist Content on the Internet

\section{Reflexões jurídicas sobre a proibição de conteúdo terrorista na internet}

Ignacio Álvarez Rodríguez* 


\section{Resumen}

El texto es una reflexión en voz alta sobre la prohibición de difusión de mensajes terroristas en internet, especialmente al hilo de las normas internacionales y nacionales en la materia. En la primera parte se analizan las normas que provienen de la Organización de las Naciones Unidas, la Unión Europea y, especialmente, del Consejo de Europa. En la segunda parte, el asunto se aborda en el marco del derecho fundamental a la libertad de expresión del artículo 20.4 de la Constitución española. En ambos casos se insistirá tanto en la jurisprudencia del Tribunal Europeo de Derechos Humanos como del Tribunal Constitucional español.

\section{Palabras clave}

Constitución; derechos fundamentales; libertades individuales; libertad de expresión; terrorismo; internet. 


\section{Abstract}

The paper reflects out loud on the prohibition to disseminate terrorist messages on the internet, especially in line with international and national standards on the subject. The first part analyzes the standards that come from the United Nations, the European Union, and, mainly, the Council of Europe. In the second part, the matter is addressed under the fundamental right to freedom of speech conferred by Article 20.4 of the Constitution of Spain. In both cases, we emphasize both the case-law of the European Court of Human Rights and the Spanish Constitutional Court.

\section{Keywords}

Constitution; fundamental rights; civil liberties; freedom of speech; terrorism; Internet. 


\section{Resumo}

Este texto é uma reflexão em voz alta sobre a proibição da difusão de mensagens terroristas na internet, especialmente à luz das normas internacionais e nacionais na matéria. Na primeira parte, são as analisadas as normas que provêm da Organização das Nações Unidas, da União Europeia e em especial do Conselho da Europa. Na segunda parte, o assunto é abordado no âmbito do direito fundamental à liberdade de expressão do artigo 20.4 da Costitução de Espanha. Em ambos os casos, é insistido tanto na jurisprudência do Tribunal Europeu de Direitos Humanos quanto no Tribunal Constitucional espanhol.

\section{Palavras-chave}

Constituição; direitos fundamentais; liberdades individuais; liberdade de expressão; terrorismo; internet. 
Sumario: 1. Planteamiento. 2. Marco jurídico internacional. 2.1. Marco jurídico de las Naciones Unidas. 2.2. Marco jurídico de la Unión Europea. 2.3. Marco jurídico del Consejo de Europa. 3. Marco jurídico nacional. 3.1. La base normativa. 3.2. Los criterios jurisprudenciales. 4. Coda: algunos argumentos para seguir reflexionando. Conclusión. Bibliografía.

\section{Planteamiento}

No caben muchas dudas al respecto: se está librando una batalla en internet por la influencia del mensaje terrorista, ya sea para captar nuevos adeptos, ya sea para publicitar sus fines y acciones, para declarar la guerra santa al infiel, para manifestar lo inevitable de una política global que quiere (¿necesita?) ir más allá del terruño. ${ }^{1}$ La realidad nos dice que los Estados han adoptado algunas medidas que intentan perseguir este tipo de mensajes, aunque no sin mediación de algunas polémicas que alimentan más que su contrastada toxicidad. ${ }^{2}$ En las siguientes líneas pretendemos hacer una reflexión en voz alta al hilo de la persecución de este tipo de contenidos desde la perspectiva del derecho constitucional, aunque no solo ceñiremos al mismo el análisis stricto sensu, máxime teniendo en cuenta que, tal y como la doctrina ha dicho, la realidad de estas armas de seducción masiva es compleja y multifacética. ${ }^{3}$

\section{Marco jurídico internacional}

La difusión de contenidos terroristas en la Red tiene su primera barrera en el derecho internacional. Va de suyo que el proyecto terrorista y la difusión de sus contenidos atenta contra la misma esencia de todo el entramado normativo e institucional existente, sea de derecho convencional, de derecho consuetu-

1 Por un lado, porque este tipo de organizaciones siguen necesitando del control de territorios concretos, a partir de los cuales puedan expandir su mensaje y sus fines, entre los cuales está el aumentar sus capacidades comunicativas. Así lo defiende M. R Torres-Soriano, "La presencia del terrorismo yihadista en Internet", Cuadernos del Centro Memorial de las Víctimas del Terrorismo 6 (2018), pp. 51 y ss. Por otro lado, porque cuando se proclama el Califato por el Daesh, los expertos detectan que la nueva estrategia global ya no se limita a zonas que controlan sino a todo Occidente (J. I. Pedrero, "La yihad virtual", Cuadernos del Centro Memorial de las Víctimas del Terrorismo, op. cit., pp. 55 y ss.).

2 Parece pertinente recordar el criterio de John Rawls que diferencia entre regular y restringir. Mientras que regular es establecer las pautas para canalizar el ejercicio de un derecho (a nuestros efectos, el de la libre expresión), restringir es impedir en ciertas condiciones que tal derecho se ejerza. Por esta razón, nadie en su sano juicio observa que cuando se establecen, pongamos por caso, los turnos de palabra en el Parlamento bajo la batuta de una presidencia que aplica las normas pertinentes para reconducir eventuales situaciones problemáticas tales reglas sean una violación de la libertad de expresión sino, al contrario, su garantía (todos pueden expresar sus puntos de vista) (J. Rawls, Teoría de la justicia, Madrid, Fondo de Cultura Económica, 1978, pp. 235 y ss.).

3 La evolución de este tipo de políticas, así como los problemas que plantean, pueden verse en M. Á. Cano Paños, "Internet y terrorismo islamista: aspectos criminológicos y legales", Eguzkilore: Cuaderno del Instituto Vasco de Criminología 22 (2008), pp. 67-88; y M. Á. Cano Paños y F. J. Castro Toledo, “El camino hacia la (Ciber) Yihad. Un análisis de las fases del proceso de radicalización islamista y su interpretación por parte de los tribunales españoles a partir de los datos suministrados por sentencias judiciales", Revista electrónica de ciencia penal y criminología 20 (2018), pp. 1-36. La afortunada expresión pertenece a Javier Lesaca y se toma del estudio de J. J. Fernández Rodríguez, “¿Cómo responder a los desafíos de seguridad? Una aproximación desde la dogmática de los derechos fundamentales", en O. Godoy (coord.), Libertad y seguridad en un contexto global. Retos y desafíos para los sistemas de garantía de los derechos fundamentales, Madrid, Dykinson, 2020, p. 31. 
dinario o del derecho internacional de los derechos humanos (DIDH). Dicho con otras palabras: la actividad terrorista supone un ataque masivo e integral a los valores que la democracia constitucional representa y, en ese sentido, "una ideología y proyecto totalitario que pretende sustituir la apertura de la búsqueda del bien común por una pretensión absoluta de verdad y dominación y aniquilar en su nombre la plural libertad de los ciudadanos" ${ }^{4}$

No obstante, y a falta de un tratado de alcance internacional sobre el fenómeno, vamos a hacer un par de apuntes respecto al marco jurídico establecido al albur de las Naciones Unidas. Posteriormente haremos lo propio con la Unión Europea, donde se negocia una de las normas que se antoja capital para la lucha contra este tipo de fenómenos en el ámbito internacional regional europeo. Finalmente, se realizarán un par de apuntes sobre el Consejo de Europa.

\section{Marco jurídico de la Organización de las Naciones Unidas}

Desde 1963, la comunidad internacional ha venido elaborando instrumentos jurídicos universales para prevenir los actos de terrorismo bajo los auspicios de las Naciones Unidas y sus organismos especializados, en particular la Organización de Aviación Civil Internacional, la Organización Marítima Internacional y el Organismo Internacional de Energía Atómica. Los instrumentos universales contra el terrorismo representan un elemento central del régimen mundial contra el terrorismo y un marco importante para la cooperación internacional. Estos instrumentos jurídicos universales abarcan actos que van desde el secuestro de aviones hasta el terrorismo nuclear por parte de personas y grupos, y obligan a los Estados que los ratifiquen a penalizar los actos terroristas más previsibles en los ámbitos cubiertos por los convenios. Sin embargo, estos instrumentos jurídicos universales son jurídicamente vinculantes únicamente para sus firmantes, quienes también se responsabilizan de hacerlos cumplir en su sistema penal. ${ }^{5}$

Ya en 1972, la Asamblea General aprueba la Resolución 3034 (XXVII), de 18 de diciembre, donde adopta, entre otras medidas, la creación del Comité Especial sobre Terrorismo Internacional y se compromete a continuar con el análisis de la materia, cosa que ha hecho puntualmente en los diferentes órdenes del día celebrados en su programa anual o bianual. Una de las principales concreciones tuvo lugar con la Resolución 60/288, de 8 de septiembre, donde se

4 La frase se toma del profesor Denninger, libremente adaptada a este contexto porque, creemos, se ajusta cual horma a zapato en lo que hace la vis destructiva de cualquier proyecto totalitario que se precie (véase E. Denninger, "Democracia militante y defensa de la Constitución", en Benda, Maihoffer, Vogel, Hesse y Heyde, Manual de Derecho Constitucional, Madrid, IVAP-Marcial Pons, 1996, p. 484).

5 Lo recuerda L. M. Díez-Picazo, Sistema de derechos fundamentales, 5 ed., Valencia, Tirant lo Blanch, 2021: a diferencia del derecho consuetudinario, que es ius cogens de obligado cumplimiento por todos los Estados, el derecho convencional solo obliga a los Estados que lo suscriben (pp. 150 y ss.). 
aprueba la "Estrategia global contra el terrorismo", en la que se sientan algunos principios basilares para luchar contra este.

Como resultado de la atención prestada a la lucha contra el terrorismo a raíz de la aprobación de la Resolución 1373 (2001) del Consejo de Seguridad, en la que el Consejo instaba a los Estados miembros a que se adhiriesen a los instrumentos jurídicos universales contra el terrorismo, el ritmo de adhesión aumentó significativamente. En junio de 2011, dos tercios de los Estados miembros habían ratificado o se habían adherido a por lo menos 10 de los 16 instrumentos universales contra el terrorismo. Y el propio Consejo de Seguridad adoptó la Resolución 2178 (2014) en la que se incide en el compromiso de los Estados de enjuiciar la financiación, planificación, preparación o comisión de actos de terrorismo, así como prestar apoyo a estos actos. ${ }^{6} \mathrm{El}$ esfuerzo ha continuado, intentando hacer frente a los desafíos que plantean esas organizaciones terroristas más o menos novedosas como el Daesh, con la Resolución 2309 (2016); o la Resolución 2370 (2017). ${ }^{7}$

Actualmente no hay ningún tratado de las Naciones Unidas contra el terrorismo que sea aplicable a una lista exhaustiva de las manifestaciones de este. Del mismo modo, la comunidad internacional todavía no se ha puesto de acuerdo sobre una definición internacional jurídicamente vinculante del término "terrorismo", debido en gran parte a la dificultad de elaborar una categorización jurídica universalmente aceptable de todos esos actos violentos que a veces perpetran los Estados, en otras ocasiones lo hacen grupos armados, algunas los denominados movimientos de liberación o de libre determinación, o los particulares. Cuestión bastante sorprendente (o a lo peor, no tanto).

Los Estados miembros vienen participando desde el año 2000 en las negociaciones relativas a una amplia convención contra el terrorismo, pero la carencia de una definición compartida única y aceptada en todo el mundo de lo que constituye terrorismo sigue siendo un muro infranqueable. No obstante, se han hecho progresos a través de los actuales instrumentos jurídicos universales, que se han desarrollado a lo largo de líneas sectoriales, con la penalización de determinados "actos terroristas". Los instrumentos universales no definen los delitos terroristas como delitos con arreglo al derecho internacional. Más bien,

\footnotetext{
Véase Fernández Rodríguez, “Cómo responder a los desafíos de seguridad?”, op. cit, pp. 47 y ss. Para la profesora Soriano, al amparo de estas resoluciones las legislaciones penales de los Estados que restringen los derechos fundamentales de la ciudadanía se convierten en una realidad que emplea la prevención como excusa para sancionar anticipadamente la posible comisión de ilícitos terroristas (Soriano Moreno, "Las reformas legislativas en los Estados miembros de la Unión Europea frente al terrorismo: análisis desde los derechos fundamentales", en O. Godoy (coord.), Libertad y seguridad en un contexto global, op. cit., pp. 89 y ss. La doctrina constitucionalista nos advierte del siempre delicado equilibrio que hay que guardar en la materia, sin caer en ese "segurinaje" que explicaba I. Torres Muro, "Terrorismo y derechos fundamentales", Revista Española de Derecho Constitucional 95 (2012), p. 450. Respecto de una de las colisiones clásicas entre derechos véase A. Sánchez Navarro, "Libertad religiosa y libertad de expresión en España", en S. Cañamares Arribas y J. Martínez-Torrón (dirs.), Tensiones entre libertad de expresión y libertad religiosa, Valencia, Tirant lo Blanch, 2014, pp. 193-205.
} 
se establece la obligación para los Estados parte en los acuerdos de penalizar en su derecho interno la conducta ilícita especificada y establecer mecanismos de cooperación internacional oportunos. En la medida en que no se concluyan con éxito las negociaciones en curso sobre una definición por todos aceptada de terrorismo, los acuerdos bilaterales y multilaterales deberán servir de base para la elaboración de normas comunes para combatir el uso de internet con fines terroristas, en aras de la promoción de la cooperación internacional.

No existe ningún convenio universal que trate específicamente de la prevención y represión del uso de internet por terroristas. En diciembre de 2010, la Asamblea General aprobó la Resolución 65/230, en la que hizo suya la “Declaración de Salvador sobre estrategias amplias ante problemas globales: los sistemas de prevención del delito y justicia penal y su desarrollo en un mundo en evolución", y solicitó a la Comisión de Prevención del Delito y Justicia Penal que creara un grupo intergubernamental de expertos de composición abierta para que realizara un estudio exhaustivo del problema del delito cibernético y de las respuestas de los Estados Miembros, la comunidad internacional y el sector privado ante ese fenómeno, incluido el intercambio de información sobre legislación nacional, mejores prácticas, asistencia técnica y cooperación internacional. Los resultados de este estudio, lanzado por la Oficina de las Naciones Unidas contra la Droga y el Delito (UNODC) en febrero de 2012, permitieron evaluar los efectos del uso de las nuevas tecnologías de la información en apoyo de actividades delictivas, en particular con respecto a ciertos usos terroristas de Internet, tales como la incitación al terrorismo y a la comisión de delitos de financiación del terrorismo por medios informáticos. ${ }^{8}$

\section{Marco jurídico de la Unión Europea}

La Unión Europea lleva lustros dedicada a la tarea de prevenir la amenaza terrorista. Desde la creación del grupo TREVI en 1976, hasta el borrador de Reglamento que vamos a exponer a continuación y que se encontraba en discusión en pleno 2020, son muchas las iniciativas que se han adoptado a su amparo. Estas iniciativas son de diversa índole, ora preceptos directamente incluidos en los tratados, ora normas de soft law, en ocasiones medidas incardinadas en la Política Común de Seguridad y Defensa, y las más de las veces estrategias que reciben diferentes nombres, pero unidas por un mismo fin que en los últimos tiempos resulta más relevante si cabe: evitar que las personas se radicalicen y sean captadas para fines subversivos terroristas y conseguir prevenir así futuras nuevas generaciones de terroristas. ${ }^{9}$ Esta cuestión no es

8 Información consultada en Organización de las Naciones Unidas, El uso de internet con fines terroristas, Ginebra, ONU, 2013, pp. 25 y ss. Véase en detalle Soriano Moreno, "Las reformas legislativas en los Estados miembros de la Unión Europea frente al terrorismo: análisis desde los derechos fundamentales", en O. Godoy (coord.), Libertad y seguridad en un contexto global, op. cit., pp. 86 y ss.

9 La idea se toma de González-Varas Ibáñez, "La posición de la Unión Europea ante la amenaza terrorista”, en O. Godoy (coord.), Libertad y seguridad en un contexto global, op. cit., p. 58. 
en absoluto baladí y la razón es bien sencilla: según los datos contrastados en los últimos estudios, se calcula que al menos una quinta parte de las personas de origen extranjero que se han incorporado al Daesh proviene de Europa occidental. En otras palabras, hablamos de una segunda generación de personas cuyas familias provienen de países en su inmensa mayoría musulmana y cuya sensación de desarraigo y desafección es palpable. Al trabajarse estas mentes, el mensaje terrorista cala en profundidad como instrumento de captación porque ofrece una cosmovisión en la cual creer, un gran objetivo colectivo por lograr $\mathrm{y}$, al fin, dota de sentido a vidas cuyos titulares creían perdidos para siempre. Terreno abonado para el proselitismo desde las redes sociales y demás nuevos medios de comunicación. ${ }^{10}$

La Unión Europea (UE) está trabajando para que tal cosa no suceda mediante una batería de medidas contra la difusión del terrorismo on line. Esta nueva legislación está en marcha, aunque no acabada (work-in-progress), por lo que advertimos al lector que a partir de ahora se extracta el borrador en su última versión y no una norma jurídica en vigor. ${ }^{11}$

La UE no es novata en estas lides y lleva tiempo luchando contra lo que algunos llaman guerra asimétrica; esto es, el empleo que hacen los terroristas de cualesquiera medios a su alcance para hacer proselitismo e infundir y sembrar lo que lamentablemente tan bien se les da: muerte, dolor y destrucción. ${ }^{12}$ Un punto de partida reseñable fue el Foro de Internet, auspiciado por la propia Unión, y que concitó a las principales empresas del sector (junto a la Comisión Europea se sentaron Google, Facebook, Twitter y Microsoft). Creado en 2015, después de una serie de atentados en suelo europeo -y especialmente después de la masacre neozelandesa de Christchurch, retransmitida en directo por las redes sociales-se comprometieron a adoptar algunas medidas voluntarias que "limpiaran la red" de contenidos terroristas. Así, en 2016 aprobaron un nuevo Código de Conducta en materia de incitación ilegal al odio en internet, con medidas como la retirada de contenidos ilegales en el plazo de 24 horas. Los cálculos más optimistas cifraron su cumplimiento en torno a un $70 \%$. Otra medida adoptada al calor de aquel acuerdo llegó en 2017 con la creación de una lista negra con huella digital de miles de imágenes, que hacía las veces

$10 \quad$ Ibid., pp. 70 y ss. Según algunos autores, se aprovecha el discurso antiterrorista y la necesidad de seguridad para abonar una política del miedo que conduzca a que el ciudadano medio acepte un recorte de sus derechos y libertades. Es de esta opinión Soriano Moreno, "Las reformas legislativas en los Estados miembros de la Unión Europea frente al terrorismo", op. cit., pp. 84 y ss.

11 Véase M. Urrea Corrales, "La respuesta internacional frente al desafío terrorista. La Unión Europea y la respuesta al terrorismo internacional", Cuadernos del Centro Memorial de las Víctimas del Terrorismo 8 (2019), pp. 72 y ss.

12 Resulta del mayor interés la reflexión que realiza Pablo de Lora, quien no considera que detrás del fundamentalismo siempre anide una parte racional, por pequeña que sea. Entiende que las creencias fundamentalistas deben ser tomadas en serio, pero también da cuenta de que no todos los autores que las estudian abogan por hacerlo de la misma manera. Por ejemplo, para Rawls se encuentran fuera del debate de la razón precisamente porque son inasibles para la misma, son inefables, traspasando esos burdens of judgment. Para autores como Habermas o Dworkin, se deben incluir en el debate público, al foro de la razón, y cohonestarlas con el resto (véase P. De Lora, "Racionalidad y fundamentalismo. Un comentario a Michael Baurmann", en Fundación Coloquio Europeo, Los desafíos de la democracia, Madrid, Fundación Coloquio Europeo, 2011, pp. 197 y ss. 
de sistema de filtrado para controlar (impedir) la difusión de imágenes con contenido de este tenor.

No obstante, había cierta preocupación. Parecía que esas medidas eran insuficientes, o parecía que se tomaban sin base legal o que podían ser más eficaces. Así que la UE recogió el guante, se puso manos a la obra y elaboró un borrador de Reglamento en 2018, cuyo contenido sigue negociándose actualmente. ${ }^{13}$

El borrador tiene enjundia propia. En primer lugar, el ámbito de aplicación personal se refiere a los prestadores de servicios de alojamiento de datos que operan dentro de la Unión (independientemente de su lugar de establecimiento o de su tamaño). En segundo lugar, la legislación propuesta introduce una serie de medidas destinadas a evitar el uso indebido de los servicios de alojamiento de datos para la difusión de los contenidos terroristas en línea, con el fin de garantizar el correcto funcionamiento del mercado único digital, así como la confianza y la seguridad de la ciudadanía. En tercer lugar, la propuesta entiende por contenido terrorista ilícito "aquella información utilizada para incitar a la comisión de delitos de terrorismo y hacer apología de dichos delitos, animando a contribuir a estos y facilitando instrucciones para cometerlos, así como promoviendo la participación en grupos terroristas". En cuarto lugar, para garantizar que se eliminan los contenidos terroristas ilícitos, se introduce una orden de retirada, que deberá ser emitida por la autoridad competente de un Estado miembro (decisión administrativa o judicial) y cumplida en una hora. En esos casos, el prestador de servicios de alojamiento de datos está obligado a retirar el contenido o bloquear el acceso al mismo en dicho plazo. Además, la propuesta exige que los proveedores de servicios de alojamiento de datos tomen medidas proactivas proporcionadas al nivel de riesgo y retiren el material terrorista de sus servicios, mediante la utilización de instrumentos de detección automatizada (en otras palabras: mediante algoritmos y sistemas de filtrados). ${ }^{14}$

Las garantías para proteger los derechos fundamentales también tienen su espacio. Como parte de las medidas de protección de los contenidos que no sean terroristas frente a una retirada errónea, la propuesta establece obligaciones de poner en marcha mecanismos de reparación y reclamación para garantizar que los usuarios puedan impugnar la retirada de sus contenidos. Además, el Reglamento introduce obligaciones en relación con la transparencia de las medidas tomadas contra los contenidos terroristas por los presta-

13 Puede hacerse el seguimiento de los avances en https://www.europarl.europa.eu/doceo/document/TA-82019-0421_ES.html, fecha de consulta: 20 de noviembre de 2020, que es de donde nos hemos basado para la exposición que se realiza seguidamente.

14 La modificación que se operó en nuestra legislación electoral en 2018 en aras de permitir que las formaciones políticas crearan bases de datos conforme a perfiles ideológicos fue declarada inconstitucional por la STC 76/2019, de 22 de mayo. Véase el pormenorizado análisis que realiza en este volumen la profesora Ferrer Martín de Vidales. También puede verse M. Á. Presno Linera, "Algoritmos y derecho electoral”, en G. M. Díaz González (coord.) y A. J. Huergo Lora (dir.), La regulación de los algoritmos, Cizur Menor, Aranzadi, 2020, pp. 163-180. 
dores de servicios de alojamiento de datos, garantizando así la rendición de cuentas frente a los usuarios, los ciudadanos y las autoridades. La propuesta también contempla que los Estados miembros garanticen que sus autoridades competentes tengan la capacidad necesaria para intervenir los contenidos terroristas en línea. Además, están obligados a informarse mutuamente y a cooperar entre sí, y pueden hacer uso de los canales establecidos por Europol para garantizar la coordinación en lo tocante a las órdenes de retirada y los requerimientos. La propuesta también impone a los prestadores de servicios de alojamiento de datos dos obligaciones adicionales; por un lado, informar con detalle sobre las medidas adoptadas, así como informar a las autoridades policiales cuando detecten contenidos que entrañen un riesgo para la vida o la seguridad; $y$, por otro, conservar los contenidos que retiren, lo cual sirve como garantía contra la retirada errónea y asegura que no se pierdan posibles pruebas a efectos de la prevención, la detección, la investigación y el enjuiciamiento de delitos de terrorismo. Recordemos que se plantea la posibilidad de recurrir la orden de retirada, así como el reconocimiento de que en determinadas circunstancias pudiera ser imposible la retirada del contenido.

La propuesta tuvo cierta oposición del Comité Económico y Social, órgano que entiende que esta debería incorporar a los proveedores de información y motores de búsqueda, así como a los sitios/redes de alojamiento. Además, las pequeñas y medianas empresas deberían tener a su disposición un plazo para adaptarse a la nueva regulación, porque adolecen de la capacidad técnica y humana de "las grandes". También llama la atención sobre la vaguedad del concepto "contenido terrorista", observando la diferencia que media entre países a la hora de saber qué comprende dicha definición. El plazo de una hora no se le antoja realista ni efectivo. Finalmente, señala las eventuales vulneraciones de derechos fundamentales, cuestión cuyo análisis es recurrente en la doctrina académica y cuya opinión mayoritaria es que en ningún caso pueden ceder sino excepcionalmente. ${ }^{15}$

La comunidad de expertos también se ha hecho oír. Por ejemplo, en 2019 Mitchell Baker (presidenta de Mozilla), Tim Berners-Lee (uno de los pioneros de la world wide web), Vint Cerf (uno de los pioneros de internet) o Jimmy Wales (creador de Wikipedia), recordaban la definición vaga y especialmente extensa del concepto de contenido terrorista, sobre todo porque no incluye ninguna excepción por motivos educativos, periodísticos o investigativos, lo cual crea el peligro de disparar por elevación y eliminar partes vitales del debate público. ${ }^{16}$ Además, estiman que adolece de poca proporcionalidad. A su juicio, la propuesta tiene mucho de tabula rasa y puede arrastrar contenidos que nada tienen de terroristas. Tampoco comparten los muy perentorios plazos. El margen de una hora para quitar los contenidos se antoja escasísimo, lo que producirá

15 Véase Fernández Rodríguez, “¿Cómo responder a los desafíos de seguridad?”, op. cit, pp. 49 y ss.

16 El origen de la world wide web se sitúa en el 6 de agosto de 1991 (véase R. González Férriz, La trampa del optimismo. Cómo los años noventa explican el mundo actual, Barcelona, Debate, 2020, pp. 99 y ss.). 
efectos claramente negativos (de nuevo, la posibilidad de sobreactuación eliminando miles de contenidos que no tienen que ver con el objetivo perseguido) y claramente desfavorables para los más pequeños del sector en favor de las multinacionales. El sistema de filtrado no acaba de convencer por ser "la" solución sin reparar en que su creación y actualización solo están al alcance de las empresas punteras. En conclusión, los firmantes consideran que cualquier norma que quiera adoptarse en estos asuntos debe proteger mucho mejor los derechos en juego y construirse en torno al criterio de la proporcionalidad, el único que permite que las compañías de diferente tamaño y posición puedan competir en el mercado europeo. ${ }^{17}$

La comunidad de juristas también ha aportado sus consideraciones. La primera de las críticas que suele hacerse es que el terrorismo internacional ha provocado que se introduzcan límites a los derechos fundamentales que hace algunos años eran impensables, especialmente en lo que hace a la libertad de expresión. ${ }^{18}$ Algunos autores creen que hay razones por las que el borrador contiene trazas de inconstitucionalidad. Por un lado, al establecer límites a derechos fundamentales, debería intervenir siempre un juez. Por otro, las empresas podrían incurrir en censura privada, lo cual también crea dudas de juridicidad. ${ }^{19}$ Incluso aceptando que las administraciones públicas -léase, cuerpos policiales- puedan gozar de ciertas competencias en la materia, lo que la Constitución no permite es que tengan la última palabra. ${ }^{20}$

La UE sigue con el procedimiento legislativo adelante. El Parlamento ha aprobado en primera lectura una revisión del texto y, por su lado, el Consejo aprobó en 2019 buena parte de las enmiendas que hizo la Cámara al texto original remitido por la Comisión. Resta esperar que el procedimiento legislativo finalice y conocer la versión final de la norma que, como Reglamento que es, se aplica directamente en los Estados miembro.

\section{Marco jurídico del Consejo de Europa}

En el ámbito regional del Consejo de Europa se destacan especialmente dos instrumentos. ${ }^{21}$ El primero es el Convenio de Prevención del Terrorismo, de

17 Véase https://www.politico.eu/wp-content/uploads/2019/04/TCO-letter-to-rapporteurs.pdf, fecha de consulta: 23 de septiembre de 2020.

18 Véase L. Díez Bueso, “La libertad de expresión en las redes sociales” 27 (2018), Revista de los Estudios de Derecho y Ciencia Política, pp. 5-16.

19 Véase G. Teruel Lozano, “Una lectura garantista de las nuevas tendencias en la lucha europea contra la difusión de mensajes terroristas en Internet", Revista de Derecho Constitucional Europeo 34 (2020), pp. 5 y ss.

20 G. Doménech Pascual, “La policía administrativa de la libertad de expresión”, Almacén de Derecho, 21 de junio de 2018, en https://almacendederecho.org/la-policia-administrativa-la-libertad-expresion, fecha de consulta: 23 de noviembre de 2020. A la fecha de cierre del presente trabajo, el TC dictó sentencia declarando inconstitucional la parte de la llamada Ley Mordaza que sometía a la autorización administrativa previa el empleo de imágenes o datos de las autoridades o miembros de las fuerzas y cuerpos de seguridad, por resultar contrario a la interdicción de censura previa ex art. 20.2 CE.

21 Véase A. Salinas Frías, "La obra convencional del Consejo de Europa en la prevención y lucha contra el terrorismo internacional", Anuario Español de Derecho Internacional 25 (2009), pp. 435-467; de la misma autora 
2005, cuya entrada en vigor en España se produjo en 2009 (y que ha sido ratificado por la UE en 2018). La cobertura jurídica para perseguir la difusión del mensaje terrorista reside básicamente en sus artículos 5, 6 y 7. El artículo 5 dirá que:

... se entenderá por "provocación pública para cometer delitos terroristas" la difusión o cualquier otra forma de puesta a disposición del público de mensajes con la intención de incitar a cometer delitos terroristas, cuando ese comportamiento, ya preconice directamente o no la comisión de delitos terroristas, cree peligro de que se puedan cometer uno o varios delitos.

El artículo 6, por su parte, establece que:

... se entenderá por "reclutamiento con fines terroristas" el hecho de incitar a otra persona a cometer o participar en la comisión de delitos terroristas, o a unirse a una asociación o a un grupo para contribuir a que estos cometan uno o varios delitos terroristas.

Finalmente, el artículo 7 entiende por:

... "adiestramiento con fines terroristas" el hecho de dar instrucciones para la fabricación o el uso de explosivos, armas de fuego u otras armas o sustancias nocivas o peligrosas, o para otros métodos y técnicas específicos con vistas a cometer delitos terroristas o a contribuir a su comisión, sabiendo que la formación facilitada tiene por objeto servir para la realización de tales objetivos.

Y los tres preceptos finalizan con la misma obligación para los Estados parte: adoptar las medidas necesarias para tipificar como delito, de conformidad con su derecho interno, las acciones que se lleven a cabo ilegal e intencionadamente en situaciones de normalidad democrática, cosa que España cumple escrupulosamente. ${ }^{22}$

El segundo es el Convenio Europeo de Derechos Humanos (CEDH) y la tutela que dispensa el Tribunal Europeo de Derechos Humanos (TEDH), especialmente de los valores protegidos por los artículos $8 \mathrm{CEDH}$ (derecho a la vida privada personal y familiar) y $10 \mathrm{CEDH}$ (derecho a la libertad de expresión e información). ${ }^{23} \mathrm{El} \mathrm{TEDH,} \mathrm{por} \mathrm{vía} \mathrm{incidental,} \mathrm{realiza} \mathrm{algunas} \mathrm{interpretaciones}$ que deben ser tenidas en cuenta cuando los Estados adopten medidas de vigilancia masiva de las comunicaciones: incluso aunque el fin esté justificado en aras de perseguir el discurso terrorista y la propaganda correspondiente

puede verse una versión actualizada en “Lucha contra el terrorismo internacional: no solo del uso de la fuerza pueden vivir los Estados", Revista Española de Derecho Internacional 68 (2), 2016, pp. 229-252.

22 Véase M. J. Roca Fernández, "La suspensión del Convenio Europeo de Derechos Humanos desde el Derecho español: procedimiento y control", en Godoy (coord.), Libertad y seguridad en un contexto global, op. cit., pp. 113 y ss.

23 Puede verse L. M. López Guerra, El Convenio Europeo de Derechos Humanos según la jurisprudencia del Tribunal Europeo de Derechos Humanos, Valencia, Tirant lo Blanch, 2021, pp. 100 y ss.; J. García Roca, La transformación constitucional del Convenio Europeo de Derechos Humanos, Cizur Menor, Aranzadi, 2019, pp. 76 y ss.; J. Casadevall, El Tribunal de Estrasburgo. Una inmersión rápida, Barcelona, Tibidabo, 2019, pp. 89 y ss. 
deben ofrecer garantías individuales, so pena de que la medida acabe por ser declarada incompatible con el Convenio (caso Big Brother c. Reino Unido, STEDH 13/09/2018).

En ese sentido, el TEDH ha diferenciado recientemente entre el discurso de odio y la incitación al odio, y parece que lo hace con toda la intención, si se tiene en cuenta cómo decide el caso Stomakhin c. Rusia, STEDH de 9/5/2018. El discurso de un periodista y activista sobre la situación chechena contra Rusia hace gala de una crítica durísima, incluyendo ciertos mensajes que glorifican el terrorismo y alientan a emplear la violencia. El Tribunal de Estrasburgo disecciona tales mensajes del resto del discurso y entiende que la incitación al odio que conllevan no queda amparada por el artículo $10 \mathrm{CEDH}$, no así el resto de mensajes, especialmente donde opina sobre la guerra y sus vicisitudes, mensajes que el TEDH comprende protegidos por el precepto. ${ }^{24}$

El TEDH también ha podido decir algo sobre la licitud convencional de cercenar el acceso a páginas web. Con carácter general, tal práctica no se atiene al Convenio y Estrasburgo suele recelar bastante de tales acciones, especialmente en contextos políticos convulsos o en el marco de sistemas donde las garantías del Estado de derecho parecen languidecer, decretando la vulneración del artículo $10 \mathrm{CEDH}$. Así sucedió en los casos Ahmet Yildirim c. Turquía (STEDH 18/12/2012); Cengiz y otros c. Turquía (STEDH 1/12/2015); y Vladimir Kharitonov c. Rusia (STEDH 23/6/2020). En el segundo de ellos se hace un alegato a favor de internet y de la importancia que tiene para el derecho contemplado en el artículo $10 \mathrm{CEDH}$, que dice así:

Internet se ha convertido en uno de los principales medios mediante los cuales los individuos ejercitan su derecho a la libre obtención y difusión de información e ideas, proveyendo de herramientas esenciales para participar en actividades y discusiones sobre asuntos políticos y asuntos de interés general [...] Aun es más, debido a la importancia de los sitios de Internet en el ejercicio de la libre expresión, a la luz de la accesibilidad y capacidad para almacenar y comunicar enormes cantidades de información, Internet desempeña un papel importante en garantizar el acceso de la sociedad a las noticias y facilita la diseminación de información en general (§ 49).

Respecto a la vigilancia de medios de correspondencia y telefónicos, el TEDH también ha insistido de largo acerca de la importancia de respetar unos mínimos garantes de las libertades convencionales. En el asunto Klaas y otros c. Alemania, STEDH 6/9/1978, el Tribunal recordaba que las medidas restrictivas de las comunicaciones son compatibles con el Convenio siempre que sean estrictamente necesarias para salvaguardar instituciones democráticas, especialmente teniendo en cuenta, decía entonces el Tribunal, la amenaza de

24 Véase M. Elósegui Itxaso, “El principio de proporcionalidad, la incitación al odio y la libertad de expresión Williamson c. Alemania y Pastörs c. Alemania", Revista General de Derecho Europeo 51 (2020), pp. 15-54. 
formas altamente sofisticadas de espionaje y terrorismo. En el caso concreto, entiende que Alemania cumple tales garantías y por ello no declara lesionado el derecho a la vida privada. Lustros después, la vigilancia masiva de las telecomunicaciones implementada por la legislación húngara no contemplaba tales salvaguardas y, por ende, el TEDH la declaró incompatible con ese derecho a la vida privada, en el caso Szabó y Vissy c. Hungría, STEDH 12/1/2016.

Conviene tener presente lo que el Tribunal de Estrasburgo dijo acerca de la licitud de perseguir ciertos discursos terroristas al hilo del asunto Leroy c. Francia, STEDH 02/10/2008 donde sentó tres criterios de la mayor importancia. El primero es la obligación convencional positiva que los Estados tienen de combatir la loa y glorificación de la violencia y el terrorismo. El segundo entiende que el discurso del odio no está protegido por la libertad de expresión en el caso de autos por la sencilla razón de que el discurso que pretende destruir la democracia no puede ser amparado por esta. El tercero no es menos importante: el TEDH entiende que una cosa es hacer una crítica política y otra glorificar el terrorismo con motivo de los ataques del 11-S; así, una cosa es criticar el imperialismo de Estados Unidos y otra muy diferente glorificar su destrucción por medio de la violencia, lo cual sitúa al infractor en una situación de solidaridad moral con los terroristas dado que celebrar un acto de violencia contra miles de civiles ofende la dignidad de las víctimas ( $\$ 40$ y ss.).

\section{Marco jurídico nacional}

Respecto al marco jurídico nacional se destacan dos grandes vectores. El primero viene determinado por las normas que regulan estas conductas. El segundo trata sobre las principales sentencias dictadas por nuestros tribunales para ventilar la responsabilidad penal de los hechos de autos.

\section{La base normativa}

Si se parte de la protección de la libertad de expresión en el artículo 20 CE, es palmario que la filosofía que inspira la iniciativa europea y el escrupuloso cumplimiento de las obligaciones internacionales por parte de España dio como resultado que se aprobara la Ley Orgánica 2/2015, donde se establece una serie de modificaciones del Código Penal que tienen como nexo de unión la persecución de la difusión de los ilícitos terroristas en internet. ${ }^{25}$ Tales mo-

25 En España, la Ley Orgánica 6/2002, de Partidos Políticos, fue la principal arma jurídica para ilegalizar al que se demostró era brazo político de la banda terrorista ETA, norma declarada constitucional por la STC 48/2003, de 12 de marzo, y confirmada en control de convencionalidad por el Tribunal de Estrasburgo. Dijo este a mayores que "los proyectos políticos del partido demandante entran en contradicción con el concepto de sociedad democrática y representan un gran peligro para la democracia española, siendo la sanción impuesta al interesado, proporcionada al objetivo legítimo perseguido en el sentido del artículo 11.2 [...]. De lo que resulta, que la disolución puede ser considerada 'necesaria en una sociedad democrática', particularmente para el 
dificaciones introdujeron, entre otros, los nuevos artículos $577.2 \mathrm{CP}, 578 \mathrm{CP}$ y 510 bis $\mathrm{CP} .{ }^{26} \mathrm{El}$ hilo conductor de todos es el castigo de quienes enaltezcan o ayuden a grupos terroristas.

\section{Los criterios jurisprudenciales}

La jurisprudencia más reciente la tenemos en la SAN 1472/2019 de 7 de mayo, y en la STS 2169/2020 de 2 de julio, que resuelve el recurso de casación interpuesto contra la primera. De especial relevancia se antoja el Fundamento de Derecho (FD) de esta última, que pasamos a extractar con la vista puesta en que hablamos de la última interpretación del alto tribunal de las normas que interesan al objeto del trabajo.

El Tribunal Supremo comienza recordando su propia jurisprudencia, más en concreto la STS 512/2017 de 5 de julio, donde se hace eco de la nueva regulación acaecida en 2015, en la que se penaliza el adoctrinamiento y la incitación al terrorismo. Recuerda también su STS 13/2018 de 16 de enero, donde ya dijo que dicha normativa pretende evitar que los terroristas puedan servirse de individuos que, sin estar incardinados en ellas, coincidan en facilitar el propósito de aquellas de subvertir el orden constitucional o de alterar gravemente la paz pública. Es interesante resaltar que el Tribunal Supremo entiende que la misma no exige

... la adhesión ideológica del que colabora con los postulados de la organización a la que presta soporte, ni tampoco que persiga determinados objetivos políticos o ideológicos, o que el sujeto pasivo de la acción se configure de una manera determinada, limitándose el precepto a proteger que la agrupación terrorista pueda verse aventajada o asistida en el desarrollo de sus métodos violentos, de suerte que el solo conocimiento de que la acción desplegada puede posibilitar, favorecer o contribuir a alterar gravemente la paz pública, atemorizando a los habilitantes de una población o a un colectivo social, satisface la esencia de la protección penal (FD 3).

\section{Continúa el alto tribunal argumentando que}

... el recurrente divulgaba un mensaje que giraba en torno a tres elementos fundamentales que configuran su responsabilidad, al contar con objetiva capacidad para

mantenimiento de la seguridad pública, la defensa del orden y la protección de los derechos y libertades de terceros" (STEDH Eusko Abertzale Ekintza-Acción Nacionalista Vasca c. España,15/01/2013, § 81). Se hizo un repaso del itinerario judicial de esta ilegalización en I. Álvarez Rodríguez, "La ilegalización de partidos políticos", en F. J. Matia Portilla (dir.), Problemas actuales sobre el control de los partidos políticos, Valencia, Tirant lo Blanch, 2016, pp. 289-340. Véase también R. Blanco Valdés, Luz tras las tinieblas. Vindicación de la España constitucional, Madrid, Alianza Editorial, 2018, pp. 193 y ss.

26 La doctrina refiere la indeterminación de algunos de los preceptos, lo cual conduce a que sean los jueces quienes sea vean abocados a integrar tales carencias. Por todos, véase M. Á. Cabellos Espiérrez, “Opinar, enaltecer, humillar: respuesta penal e interpretación constitucionalmente adecuada en el tiempo de las redes sociales", Revista Española de Derecho Constitucional 112 (2018), pp. 53 y ss. Respecto al discurso del odio véase F. Valiente Martínez, La democracia y el discurso del odio. Límites constitucionales a la libertad de expresión, Madrid, Dykinson, 2020. 
que puedan germinar o potenciarse las convicciones que terminen por impulsar la determinación del instigado hacia los violentos axiomas que el acusado divulgaba: 1) la existencia de crueles e infundados ataques a los musulmanes, lo que conforme a su discurso suscita la necesidad de una reacción defensiva; 2) la obligación que tiene un buen musulmán de acabar con la vida de cuantos no compartan su fe y 3) el heroico elogio a quienes se incorporan a la yihad o a la acción de algunas de las organizaciones terroristas que la proclaman, como el Estado Islámico o Al Qaeda (FD 3).

\section{Al Tribunal Supremo no le genera ninguna duda que}

... esta actuación de difusión ideológica y violenta, responde, como también se declara probado, a distintas actividades que el Daesh despliega para la consecución de sus fines, concretamente consistente en la intensa propaganda de sus acciones y su organización, proselitismo, captación de nuevos miembros, adoctrinamiento ideológico, adiestramiento operativo; [...] siendo significativo que tuviera un blog con 113.569 seguidores, y perfiles en Facebook con 2.393 seguidores, efectuando difusiones en Blogspot, Google +, Facebook, Twitter y Youtube, participando como administrador de varias cuentas y como simple usuario de otras". Todo ello, culminado su participación colaborativa con el adiestramiento indiscriminado de personas para la actuación terrorista, al haber difundido videos en los que facilitaba pautas de entrenamiento para la utilización en combate de machetes o cuchillos, así como de la katana japonesa (FD 3).

Se impone ahora hacer una reflexión desde la jurisprudencia constitucional, aunque obligadamente somera por razones de espacio. Recordemos que el derecho fundamental a la libertad de expresión está reconocido como un derecho limitado por los valores contemplados en el artículo 20.4 CE. Unos límites que muestran tal grado de apertura e indeterminación que, de ser interpretados literalmente, probablemente vaciarían de contenido el derecho. ${ }^{27}$ El Tribunal Constitucional ha dictado una valiosa y garantista jurisprudencia del precepto, muy ligada a la idea de dimensión objetiva que supone para el orden democrático en su conjunto: no solo protege la libertad de cada persona de expresarse como estime, sino también entiende que estamos ante la auténtica garantía de la formación de una opinión pública libre y plural, por ende vital para la democracia (la STC 6/1981 es la primera en la materia y la más señera). ${ }^{28}$ En la materia que nos ocupa, la difusión de un contenido claramente terrorista -que busque subvertir el orden político mediante la violencia y el asesinato- no parece plantear especiales problemas a la hora de su prohibición legal siendo como es un atentado contra el corazón de la democracia. El problema reside más bien cuando el mensaje es apologeta, de promoción, donde existe una duda auténtica y real de si se está haciendo proselitismo de la causa

27 Véase Díez-Picazo, Sistema de derechos fundamentales, op. cit., pp. 168 y ss. No es infrecuente que estas polémicas también se enmarquen en torno a la libertad ideológica y el orden público, límite este que ha estudiado en profundidad Fernando González Botija, Orden público y libertad, Barcelona, Atelier, 2018. 
terrorista o expresando una opinión, esa siempre delgadísima línea roja. En los últimos tiempos, la cuestión se ha discutido en el marco del discurso del odio, un concepto complejo y brumoso como pocos. A los efectos del objeto de este trabajo, destacaremos algunas ideas derivadas de nuestra jurisprudencia constitucional, en el bien entendido de que nos encontramos ante una casuística muy idiosincrática, por escasa y por particularmente difícil de resolver con carácter definitivo.

Dejando de lado los orígenes y el desarrollo del discurso del odio en esa jurisprudencia constitucional -límite a la libertad de expresión que, dicho sea de paso, no figura como tal dentro de la Constitución- respecto al enaltecimiento del terrorismo tenemos tres resoluciones que merece la pena comentar. Hablamos del caso Stern Taulats; del caso Erkizia y del caso Strawberry. La primera es la STC 177/2015 (caso Stern Taulats y Roura Capellera) donde se resuelve la licitud constitucional del castigo penal a dos sujetos que quemaron públicamente las imágenes de los reyes de España. Como sabemos, los demandantes llegaron en amparo internacional ante el TEDH y este les reconoció que se lesionó su derecho a la libertad de expresión. El Tribunal Constitucional entendió otra cosa: que el hecho de quemar fotos de los reyes en público, con la cara tapada, incita al odio y, por ese motivo, la sanción penal impuesta a resultas de ello es una injerencia legítima en el derecho fundamental a la libertad de expresión (FJ 4 y ss.). Lo más sintomático del asunto es que esa sanción penal parecía respetar los cánones de proporcionalidad de Estrasburgo, según interpretó el propio Tribunal Constitucional. Dado que aquella se ha rebajado finalmente, y aplicando con generosidad los criterios que derivan de un acopio importante de jurisprudencia convencional, nuestro juez de la Constitución entiende que no se lesiona la libertad de expresión ni la libertad ideológica (FJ 5). La minoría discrepante no comparte ese y casi ningún otro criterio de la mayoría, tal y como ejemplifican los votos particulares de los magistrados Asúa Batarrita y Valdés-Dal Ré, así como el del magistrado Xiol Ríos, que hacen una lectura diferente de la jurisprudencia del TEDH (especialmente a la luz del señero asunto Feret c. Bélgica, STEDH de 16/07/2009). ${ }^{29}$ No es un caso de apología del terrorismo, pero sí es una interpretación expansiva del discurso del odio que, de seguir dicha senda, quedaría amparado por este.

La segunda resolución a la que se aludía antes es la STC 112/2016 (caso Taso Erkizia), de la que no tenemos todavía noticias desde Estrasburgo pero las tendremos en un futuro cercano. ${ }^{30} \mathrm{El}$ caso tiene que ver con un acto público de

29 Según la Recomendación núm. R (97) 20 del Consejo de Europa, el discurso del odio “abarca cualquier forma de expresión que propague, incite, promueva o justifique el odio racial, la xenofobia, el antisemitismo u otras formas de odio basadas en la intolerancia que se manifiestan a través del nacionalismo agresivo y el etnocentrismo, la discriminación y la hostilidad contra las minorías y los inmigrantes o personas de origen inmigrante", en el asunto Feret puede verse la reproducción literal en el $\S 44$.

30 El asunto Erkizia Almandoz ha sido ya comunicado al Gobierno español, mediante decisión del TEDH de 28 de marzo de 2017. https://hudoc.echr.coe.int/eng\#\{\%22fulltext\%22:[\%22erkizia\%22],\%22item 
homenaje a un terrorista. El Sr. Erkizia es imputado y finalmente condenado en vía penal por un delito de enaltecimiento del terrorismo. ${ }^{31}$ Recurre en amparo ante el TC alegando que se ha vulnerado su derecho a la libre expresión y a la libertad ideológica. El TC decide, dicho de forma muy resumida, acudiendo explícitamente a los criterios del TEDH. Citando de nuevo jurisprudencia convencional (en concreto la línea seguida en el asunto Hogefeld c. Alemania, STEDH de 20/01/2000), nuestro juez de la Constitución entiende que el TEDH admitió como sanción penal compatible con el Convenio la incitación a la comisión de actos terroristas violentos (FJ 3). A mayor abundamiento, nuestro juez de la Constitución lista una serie de casos decididos por el TEDH donde se dijo que sanciones penales similares a las de autos eran compatibles con el artículo $10 \mathrm{CEDH}$. Por ejemplo, si la conducta es un riesgo para la seguridad nacional, la integridad territorial o la seguridad pública (asunto Leroy c. Francia, STEDH de 02/10/2008), o si la sanción trae causa de mostrar apoyo moral a la actividad, a la ideología, o por realizar cualquier tipo de loa o alabanza hacia actos terroristas (por todos, asunto Zana c Turquía, STEDH de 08/07/1999). Tomando en cuenta estos criterios, el TC considera que la sanción penal es una injerencia legítima en la libertad de expresión, por ser "manifestaciones del discurso del odio por propiciar o alentar, aunque sea de manera indirecta, una situación de riesgo para personas o derechos de terceros o para el propio sistema de libertades" (FJ 4). ${ }^{32}$ La resolución cuenta con el voto particular del magistrado Xiol Ríos, quien hace una lectura diametralmente opuesta de la jurisprudencia de Estrasburgo.

El último capítulo hasta la fecha ha llegado con la STC 35/2020, el llamado caso Strawberry, donde el Tribunal Constitucional decide que varios tuits donde su autor decía hacer humor "nihilista-surrealista" con las víctimas del terrorismo, por más que puedan ser desafortunados, entran dentro de la libertad de expresión. El Tribunal Supremo consideró probado que el acusado había cometido delito de enaltecimiento de terrorismo por incurrir en discurso del odio (STS 4/2017, de 18 de enero). El condenado recurre en amparo alegando que se ha vulnerado su derecho fundamental a la libertad de expresión, entre otros. El Tribunal Constitucional recuerda, en primer término, la jurisprudencia constitucional y convencional sobre el mentado derecho. Destaca en ese repaso dos aspectos cruciales. El primero es la importancia del juicio de proporcionalidad a la hora de evaluar si se ha traspasado la línea, entrando en el

id\%22:[\%22001-173241\%22]\}, fecha de consulta: 20 de noviembre de 2020 .

31 El Tribunal Supremo ha dejado claro que la interpretación del delito de enaltecimiento del terrorismo, recogido en el artículo $578 \mathrm{CP}$, "no está exenta de dificultades". Un desarrollo argumentado de tales dificultades se encuentra en la STS 4/2017, de 18 de enero (FD 2⿳⺈⿴囗十一), donde condena precisamente al demandante que llega en amparo al TC en el caso Strawberry.

32 Según el penalista R. Alcácer Guirao, "Discurso del odio, protección de minorías y sociedad democrática", Revista Crítica Penal y Poder 18 (2019), p. 25, solo se debe emplear la represión penal "ante la incitación directa a la violencia y a actos concretos de discriminación que constituyan delito. También ante insultos directos a personas concretas, desconectados de un discurso sobre aspectos con relevancia pública. Y, por supuesto, ante amenazas concretas que lesionen la libertad de las personas". 
terreno del delito de enaltecimiento de terrorismo. El segundo es que, dentro de ese juicio, entiende que los criterios convencionales, citados profusamente en la resolución, entienden que para que estemos ante un discurso del odio deben concurrir diversos factores, como la intención comunicativa del emisor, el grado de difusión del mensaje, el medio elegido para ello, el mayor o menor impacto en la opinión pública, o las lesiones a bienes y derechos de terceros, entre otros (FJ 4).

Aplicados tales criterios al caso concreto, el Tribunal entiende que se ha vulnerado la libre expresión porque el Tribunal Supremo no pondera "con la intensidad exigida por la jurisprudencia constitucional las circunstancias concurrentes en el caso" (FJ 5), especialmente, respecto de la dimensión institucional de esta libertad, fundamental para el sistema democrático en su conjunto. Al eludir este examen, dice el TC, el Tribunal Supremo no tiene en cuenta que las expresiones pudieran ser manifestación del pluralismo político, ni que quizá puedan soportar opiniones políticas legítimas, por más que tengan aspectos reprobables. A juicio del TC, el imperativo constitucional no permite extraer conclusiones penales de estos elementos (FJ 5). El Tribunal Constitucional llega a la conclusión de que

... la sentencia condenatoria no ha dado cumplimiento con la necesaria suficiencia a la exigencia de valoración previa acerca de si la conducta enjuiciada era una manifestación del ejercicio del derecho fundamental al negar la necesidad de valorar, entre otros aspectos, la intención comunicativa del recurrente en relación con la autoría, contexto y circunstancias de los mensajes emitidos. Esta omisión, por sí sola, tiene carácter determinante para considerar que concurre la vulneración del derecho a la libertad de expresión del demandante de amparo (FJ 5).

El magistrado Montoya Melgar emite voto particular donde discrepa del parecer mayoritario entendiendo que el Tribunal Supremo ponderó correctamente la conducta enjuiciada.

\section{Coda: algunos argumentos para seguir reflexionando}

El terrorismo que venimos sufriendo en las últimas décadas se basa, entre otros elementos que buscan infundir terror, en una brutal espectacularidad teatral, tanto contra las personas (decapitaciones retransmitidas en directo o desmembramientos accesibles mediante la Deep web) como contra los bienes públicos (voladura de edificios, derribo de aviones, destrozos para siempre del demanio público calificado de Patrimonio de la Humanidad). En fin, técnicas que solo buscan amedrentar e infundir terror a la población, probablemente porque en lo más íntimo de sus convicciones saben que libran una guerra que no podrán ganar. Si es verdad que la mejor forma de publicitarse hoy es la red, también vale eso para sus acciones. Así que limitar la publicidad del terrorismo en esta debería ayudar a combatirlo dado que le restamos la espec- 
tacularidad (o parte de ella) y así el número de adeptos disminuye, al menos potencialmente (y la población vive un poco más tranquila). ${ }^{33}$

Todo lo que se persiga legalmente es algo que no se perseguirá ilegalmente. Y los Estados deben mantener la cabeza muy fría a la hora de combatir esta lacra. Precisamente, lo que buscan los terroristas es provocar que el Estado tenga una reacción desmedida y generar el caldo de cultivo que retroalimenta la espiral de violencia. Los terroristas nunca han negado ni han querido esconder que cuanto peor, mejor. Qué duda cabe de que perseguir la difusión de los contenidos terroristas en la red redunda en una mejor convivencia. Las buenas ideas merecen ser repetidas. Recordemos: los Estados modernos han tenido un éxito sin paliativos a la hora de erradicar la violencia política de su día a día. Por eso nos sobrecoge tanto un atentado terrorista, porque no estamos acostumbrados, al ser la vida en democracia, en líneas generales, pacífica.

Una de las mejores maneras de combatir el terrorismo es mediante una estrategia multifocal, en todo caso discreta y silente. Harari propone varias, como, por ejemplo, la acción constante de los gobiernos sin fuegos artificiales, alejar la histeria y la alarma de los medios de comunicación, o ayudar a los individuos a que pongan el asunto en perspectiva. ${ }^{34}$ De conseguirlo es muy probable que el caldo de cultivo del que se alimenta el populismo disminuya, populismo que anida detrás de todo proyecto terrorista. Autores como David Runciman entienden que determinadas posiciones populistas se valen de la sensación de inseguridad que reina gracias a explorar la sedicente "amenaza terrorista". Es decir: nuestras sociedades experimentan cada vez menos violencia real pero, simultáneamente, se exponen a niveles crecientes de violencia mediática. Somos más espectadores que nunca de la violencia mientras que estamos en mínimos históricos en lo que hace a sufrirla directamente, lo cual desemboca en cierta paranoia y ansiedad. ${ }^{35}$ Esta paranoia y ansiedad siembran el terreno para que los discursos populistas "hagan su agosto". Eliminando contenidos terroristas de la red es muy probable que contribuyamos a reducir la diferencia entre la una y la otra y, sobre todo, consigamos ponérselo más difícil a ese discurso antiterrorista demagogo que se aprovecha del miedo. Algunos estudios científicos demuestran que la tecnología digital -dicho así, en general-ha implicado un aumento de la violencia política en ciertas zonas del globo. Así lo asevera el politólogo de Harvard Yascha Mounk. ¿El motivo? Que cierra la brecha entre los que están en el poder (Estado) y los que están fuera (rebeldes, terroristas). Si un grupo terrorista da a conocer lo que hace impunemente re-

33 Para Todorov, partiendo de que tal espectacularidad es cierta, el terrorismo islámico no es un candidato creíble para ocupar el papel de Moscú en el pasado porque ningún modelo de sociedad no democrática se presenta, al día de hoy, como rival de la democracia. Al contrario, se aspira a la misma allá donde no existe. Y eso -deducimos nosotros de su pensamiento- significa que la pulsión destructiva se agota en sí misma, sin solución de continuidad, sin que este tipo de acciones o mensajes vayan a traer jamás un modelo realmente democrático (véase T. Todorov, Los enemigos íntimos de la democracia, Barcelona, Galaxia Gutenberg, 2012, pp. 9 y ss.).

34 Y. N. Harari, 21 Lecciones sobre el siglo XXI, Barcelona, Debate, passim.

35 D. Runciman, Así termina la democracia, Barcelona, Paidós, 2019, pp. 120 y ss. 
duce mucho la distancia con el gobierno que de manera democrática hemos elegido y acaba por disputarle su legitimidad. Que es tanto como decir que al conjunto del sistema democrático, hecho que resulta muy poco justo y mucho menos limpio si se repara en que cambiar las reglas del juego exige cumplirlas y no destruirlas. ${ }^{36}$

Eliminando contenidos terroristas podemos mitigar el efecto "cámara de resonancia" o "de eco". Esta idea se refiere a que las personas nos unimos cual enjambre en la red, esto es, con personas que opinan de forma muy similar a la nuestra para ver reafirmados antes que cuestionados nuestros postulados. Evitar la propaganda y glorificación del terrorismo on line podrá poner un ladrillo más en el muro de la prevención de la retroalimentación del caldo de cultivo terrorista. ${ }^{37}$

En fin, esparcir y glorificar el mensaje terrorista solo contribuye a crear lo que se denomina sociedades del desprecio, donde la dignidad de la sociedad en su conjunto, nuestro valor más preciado e intrínseco como seres humanos, se vería puesta en tela de juicio. Si dejamos que el discurso terrorista circule libremente por la red estaremos dejando que se introduzca una carga de muy alto voltaje en nuestra vida cotidiana que acabará por minar la moral del más paciente y polarizará los debates que se tercien. No es que con esta actitud ayudemos a normalizarlo -que también-, sino que elevamos los niveles de ruido y de caos hasta extremos que hacen irrespirable la convivencia. El terrorismo, ya sea en su vertiente off line $\mathrm{u}$ on line, alimenta la única sociedad que puede: la sociedad del desprecio. ¿Quién podría o querría vivir en una sociedad así? ${ }^{38}$

Ahora vamos -for the sake of argument, como diría un anglosajón- a reflexionar sobre argumentos que no son tan buenos para la persecución de estos contenidos.

Por un lado, las democracias constitucionales son bastiones para la defensa y la garantía de la libertad. Y prohibir debería estar reservado a cuestiones realmente excepcionales. Aun siendo el tema que tratamos una de esas ocasiones excepcionales, intuitivamente algo chirría al unir democracia y prohibición. Si prohibimos lo que nos repugna, máxime en los tiempos que corren, contribuimos a potenciar ese clima neocensor que tantos adeptos reúne en torno a la idea de la cultura de la cancelación. La línea que existe en la práctica entre

36 Y. Mounk, El pueblo contra la democracia, Barcelona, Paidós, 2019, passim. Estudios recientes nos informan que el objetivo de organizaciones como Daesh o Al-Qaeda -quizá más de la primera- es realizar un "llamamiento a la población islámica mundial, una especie de territorio con el magnetismo suficiente como para provocar un cambio en el panorama político del mundo árabe-musulmán, que ese es al fin y al cabo el objetivo último" (M. R. Torres Soriano, "Del califato terrenal al califato virtual", Cuadernos del Centro Memorial de las Víctimas del Terrorismo 8 [2019], p. 19).

37 Lo explica C. Sunstein, República.com. Internet, democracia y libertad, Barcelona, Paidós, 2003.

38 Véase Valiente Martínez, La democracia y el discurso del odio, op. cit., passim. 
lo que es una defensa y apología, una opinión subida de tono, o una broma o chiste, es en ocasiones tan fina que hace imposible enunciar criterios generales e incontrovertibles. ${ }^{39}$

Por otro, si hablamos del discurso del odio en general, el requisito para sancionarlo sería cumplir el criterio de Brandenburg, que se basa en la incitación clara, directa e inminente de la violencia. Como criterio jurídico es uno de los principios que más se han discutido y que menos claro resulta, lo cual Michael Sandel demuestra: dice el filósofo que si estos casos se judicializan, en última instancia será el criterio moral del juez el que decida el litigio; y no puede ser de otro modo, querámoslo o no. Es decir, para muchos, un criterio extrajurídico o metajurídico. ${ }^{40} \mathrm{Si}$ a eso le unimos que buena parte de estos casos suelen hacer bueno el aforismo que reza hard cases make bad law y, para más señas, que la moralidad es cambiante en tiempo y espacio (especialmente en tiempos y espacios donde nos la podemos permitir tal y como recuerda John Gray), volvemos a toparnos con la dificultad de proclamar reglas generales asertivamente. ${ }^{41}$

Por último, no conviene olvidar el efecto Streisand en su variante terrorista: al denunciar y dar espacio a ciertas acciones terroristas, espectaculares y aterradoras, no hacemos sino ayudar a que permanezcan en nuestras cabezas y retinas, $\mathrm{y}$, en definitiva, en el debate público, dándoles un pábulo y una relevancia que a la larga solo acaban por engordar a la bestia. Los medios de comunicación del siglo XXI son tan amplios y variados, y los miles de conversaciones tan líquidas, que quizá deberíamos plantearnos si la mejor solución pasaría por dejar que se fueran espontánea y naturalmente por el desagüe, valga la desabrida expresión. El riesgo de llevarnos por delante valores que son fundamento del orden político y la paz social en aras de combatir acciones execrables que, de tener éxito, destruirían ese orden político y esa paz social siempre penderá cual espada de Damocles encima de nuestras cabezas.

\section{Conclusión}

Como reflexión final, cabe decir que es posible que las labores para preservar nuestras democracias tendrán mucho que ver con el hecho de que la habiten demócratas convencidos. Si esto no sucede, las medidas de prevención no llegarán a calar y las medidas represivas serán el ínterin entre la renovación de unos cuadros terroristas por otros. Y mientras eso sucede, estos ganan expansión

39 Véase A. Kaiser, La neoinquisición. Persecución, censura y decadencia cultural en el siglo XXI, Barcelona, Deusto, 2020, pp. 206 y ss.

40 Véase M. Sandel, Filosofía pública, Barcelona, Marbot, 2008, p. 315, argumento que confronta con dos casos límite que acaecieron en Estados Unidos, como fueron la manifestación nazi de Skokie y la marcha encabezada desde Selma a Montgomery por Martin Luther King. Para nuestro filósofo, cuando los jueces deben decidir este tipo de litigios lo hacen siguiendo criterios no neutrales y sí morales que justifican el derecho a expresarse libremente, lo cual, a su mejor entender, sugiere que a grandes problemas mayor margen para la libertad.

41 Véase J. Gray, Perros de paja. Reflexiones sobre los humanos y otros animales, Barcelona, Paidós, 2008, especialmente el capítulo 3, "Los vicios de la moral", pp. 91 y ss. 
e influencia, con internet como la principal forma de comunicar, adoctrinar, reclutar y animar a seguir ampliando el "espacio vital" que le corresponde a tamaño proyecto. Mucho nos tememos que se vuelve a demostrar que la única democracia realmente posible es aquella donde ciudadanos e instituciones defienden los valores sobre los que se asienta. La normativa internacional y nacional intenta cortar el paso a las vías de comunicación de los terroristas $\mathrm{y}$, en dicho sentido, los esfuerzos están encima de la mesa y habrá que hacer un análisis reposado de sus réditos y fallas. Al igual que solo los demócratas construyen democracia, solo los demócratas pueden defender a la democracia de sus enemigos.

\section{Bibliografía}

Alcácer Guirao, R., “Discurso del odio, protección de minorías y sociedad democrática", Revista Crítica Penal y Poder 18 (2019).

Álvarez Rodríguez, I., “La ilegalización de partidos políticos”, en F. J. Matia Portilla (dir). Problemas actuales sobre el control de los partidos políticos, Valencia, Tirant lo Blanch, 2016.

Blanco Valdés, R., Luz tras las tinieblas. Vindicación de la España constitucional, Madrid, Alianza Editorial, 2018.

Cabellos Espiérrez, M. Á., “Opinar, enaltecer, humillar: respuesta penal e interpretación constitucionalmente adecuada en el tiempo de las redes sociales", Revista Española de Derecho Constitucional 112 (2018).

Cano Paños, M. Á., "Internet y terrorismo islamista: aspectos criminológicos y legales", Eguzkilore: Cuaderno del Instituto Vasco de Criminología 22 (2008).

Cano Paños, M. Á. y Castro Toledo, F. J., “El camino hacia la (Ciber)Yihad. Un análisis de las fases del proceso de radicalización islamista y su interpretación por parte de los tribunales españoles a partir de los datos suministrados por sentencias judiciales", Revista electrónica de ciencia penal y criminología 20 (2018).

Casadevall, J., El Tribunal de Estrasburgo. Una inmersión rápida, Barcelona, Tibidabo, 2019.

De Lora, P., "Racionalidad y fundamentalismo. Un comentario a Michael Baurmann", en Fundación Coloquio Europeo, Los desafíos de la democracia, Madrid, Fundación Coloquio Europeo, 2011.

Denninger, E., “Democracia militante y defensa de la Constitución”, en Benda, Maihoffer, Vogel, Hesse y Heyde, Manual de Derecho Constitucional, Madrid, IVAP-Marcial Pons, 1996. 
Díez Bueso, L., "La libertad de expresión en las redes sociales”, Revista de los Estudios de Derecho y Ciencia Política 27 (2018).

Díez-Picazo, L. M., Sistema de derechos fundamentales, 5 ed., Valencia, Tirant lo Blanch, 2021.

Doménech Pascual, G., "La policía administrativa de la libertad de expresión”, Almacén de Derecho, 21 de junio de 2018, en https://almacendederecho.org/ la-policia-administrativa-la-libertad-expresion

Elósegui Itxaso, M., “El principio de proporcionalidad, la incitación al odio y la libertad de expresión en la reciente Jurisprudencia del Tribunal Europeo de Derechos Humanos: los Casos Stomakhin c. Rusia, Williamson c. Alemania y Pastörs c. Alemania", Revista General de Derecho Europeo 51 (2020).

Fernández Rodríguez, J. J., “ ¿Cómo responder a los desafíos de seguridad? Una aproximación desde la dogmática de los derechos fundamentales", en $\mathrm{O}$. Godoy (coord.), Libertad y seguridad en un contexto global. Retos y desafíos para los sistemas de garantía de los derechos fundamentales, Madrid, Dykinson, 2020.

García Roca, J., La transformación constitucional del Convenio Europeo de Derechos Humanos, Cizur Menor, Aranzadi, 2020.

González Férriz, R., La trampa del optimismo. Cómo los años noventa explican el mundo actual, Barcelona, Debate, 2020.

González Botija, F., Orden público y libertad, Barcelona, Atelier, 2018.

González-Varas Ibáñez, A., “La posición de la Unión Europea ante la amenaza terrorista", en O. Godoy (coord), Libertad y seguridad en un contexto global. Retos y desafíos para los sistemas de garantía de los derechos fundamentales, Madrid, Dykinson, 2020.

Gray, J., Perros de paja. Reflexiones sobre los humanos y otros animales, Barcelona, Paidós, 2008.

Harari, Y. N., 21 Lecciones sobre el siglo XXI, Barcelona, Debate, 2018.

Kaiser, A., La neoinquisición. Persecución, censura y decadencia cultural en el siglo XXI, Barcelona, Deusto, 2020.

López Guerra, L. M., El Convenio Europeo de Derechos Humanos según la jurisprudencia del Tribunal Europeo de Derechos Humanos, Valencia, Tirant lo Blanch, 2021.

Mounk, Y., El pueblo contra la democracia, Barcelona, Paidós, 2019.

Organización de Naciones Unidas, El uso de internet con fines terroristas, Ginebra, ONU, 2013. 
Pedrero, J. I., "La yihad virtual", Cuadernos del Centro Memorial de las Víctimas del Terrorismo 6 (2018).

Presno Linera, M. Á., "Algoritmos y derecho electoral”, en G. M. Díaz González, (coord.) y A. J. Huergo Lora (dir.), La regulación de los algoritmos, Cizur Menor, Aranzadi, 2020.

Rawls, J., Teoría de la justicia, México, Fondo de Cultura Económica, 1978.

Roca Fernández, M. J., “La suspensión del Convenio Europeo de Derechos Humanos desde el Derecho español: procedimiento y control", en O. Godoy (coord.), Libertad y seguridad en un contexto global. Retos y desafíos para los sistemas de garantía de los derechos fundamentales, Madrid, Dykinson, 2020.

Runciman, D., Así termina la democracia, Barcelona, Paidós, 2019.

Salinas Frías, A., "La obra convencional del Consejo de Europa en la prevención y lucha contra el terrorismo internacional”, Anuario Español de Derecho Internacional 25 (2009).

Salinas Frías, A., "Lucha contra el terrorismo internacional: no solo del uso de la fuerza pueden vivir los Estados", Revista Española de Derecho Internacional 68 (2) (2016).

Sánchez Navarro, Á., "Libertad religiosa y libertad de expresión en España”, en S. Cañamares Arribas y J. Martínez-Torrón (dirs), Tensiones entre libertad de expresión y libertad religiosa, Valencia, Tirant lo Blanch, 2014.

Sandel, M., Filosofía pública, Barcelona, Marbot, 2008.

Soriano Moreno, S., "Las reformas legislativas en los Estados miembros de la Unión Europea frente al terrorismo: análisis desde los derechos fundamentales", en O. Godoy (coord.), Libertad y seguridad en un contexto global. Retos y desafíos para los sistemas de garantía de los derechos fundamentales, Madrid, Dykinson, 2020.

Sunstein, C., República.com. Internet, democracia y libertad, Barcelona, Paidós, 2003.

Teruel Lozano, G., "Una lectura garantista de las nuevas tendencias en la lucha europea contra la difusión de mensajes terroristas en Internet", Revista de Derecho Constitucional Europeo 34 (2020).

Todorov, T., Los enemigos íntimos de la democracia, Barcelona, Galaxia Gutenberg, 2012.

Torres Muro, I., “Terrorismo y derechos fundamentales”, Revista Española de

Derecho Constitucional 95 (2012). 
Torres-Soriano, M. R., "La presencia del terrorismo yihadista en Internet", Cuadernos del Centro Memorial de las Víctimas del Terrorismo 6 (2018).

Torres-Soriano, M. R., “Del califato terrenal al califato virtual”, Cuadernos del Centro Memorial de las Víctimas del Terrorismo 8 (2019).

Urías, J., La libertad de expresión. Una inmersión rápida, Barcelona, Tibidado, 2019.

Urrea Corrales, M., “La respuesta internacional frente al desafío terrorista. La Unión Europea y la respuesta al terrorismo internacional", Cuadernos del Centro Memorial de las Víctimas del Terrorismo 8 (2019).

Valiente Martínez, F., La democracia y el discurso del odio. Límites constitucionales a la libertad de expresión, Madrid, Dykinson, 2020. 